\title{
Associational Strategies for European SMEs' Internationalization: Introducing the Meta- Organization as a Multi-Level Unit of Analysis
}

\author{
Calin Gurau ${ }^{1, *}$, Leo-Paul Dana ${ }^{1, *}$ \\ ${ }^{1}$ Montpellier Business School, Montpellier Research in Management (MRM), France
}

\begin{abstract}
In the past, entrepreneurs could prosper as owner-managers of independent local businesses. As a consequence, the unit of analysis in business research has typically been - and continues to be - the entrepreneur and/or the enterprise. Yet, the reality of the global marketplace has been changing, as formerly competing firms are now co-operating in various types of horizontal, vertical or trans-industry alliances. Growth need not take place by means of mergers and acquisitions, but can also be attained via networking, leading to a multi-polar distribution of ownership and control. The individual firm is no longer the most important player being substituted by associations, groups or networks. To reflect the changing reality, we investigate the concept of meta-organizations as a potential platform for the internationalization of European SMEs; we do this, using an inductive approach that mobilizes and interprets a wide range of business theories on in the areas of internationalization, entrepreneurship, organization and economics.
\end{abstract}

Keywords: SMEs, internationalization, network theory, inter-organizational relations, metaorganization

\section{Introduction}

Globalization results from the removal of restrictions on foreign trade, investment, and innovations in various sectors (Paul, 2015). This trend creates new opportunities and challenges for small and medium-sized enterprises (SMEs) (Paul et al., 2017). On the one hand, low transportation and communication costs, the fragmentation and evolution of markets, and the availability of data and consulting services, allow SMEs to identify interesting business opportunities located in foreign markets (Dana et al., 1999). However, the small size, limited market power, lack of resources and high specialization of SMEs, often limits their capacity to access and exploit large-scale international opportunities as independent organizations. The high level of globalization and competition that characterizes many domestic markets compounds this problem, transforming SMEs' internationalization into a matter of survival (Dana et al., 1999). This situation is particularly relevant for European SMEs, which have a smaller domestic market than do US firms (Gurau \& Ranchhod, 2007). 
To fill the gap between their level of organizational resources and the scale of international business opportunities, some SMEs use associational strategies; by creating or adhering to group of firms, they participate as members to the design and implementation of international business strategies (Wright \& Dana, 2003). Paradoxically, some of these SMEs may not realize any direct international transactions, but can take advantage of international business opportunities through their membership in an international meta-organization. This situation requires a shift of research perspective, with the unit of analysis shifting to the metaorganization, that represents, on the one hand, a collective actor of internationalization and cross-border transactions, and, on the other hand, the institutional context in which individual SMEs act and interact with other organizations. Despite the increasing popularity of these associational strategies, the extant research is still largely focused on either the firm or the individual entrepreneur (Wright et al., 2007), while the role and functioning of metaorganizations is scarcely addressed in internationalization research (Viachka, 2013).

We address this knowledge gap, advocating and justifying the use of meta-organizations (Ahrne \& Brunsson, 2008) as alternative units of analysis of international business processes. Using an inductive approach applied to the extant literature on SMEs' internationalization, our paper (i) provides a critical overview of the existing research streams; (ii) builds the arguments for a new research paradigm centred on meta-organizations; and (iii) makes propositions for the research topics that needs to be addressed both from an economic and managerial perspective.

This paper provides an original contribution to the SME internationalization literature, conceptualizing, describing and modelling an alternative research paradigm based on metaorganizational institutions. Although these meta-organizations represent consensual associations of SMEs and other types of organizations (public agencies, universities, local and national administration), they are more than the sum of their members, creating another level of organization, strategic planning and tactical action. Despite its theoretical approach, our study provides a series of practical recommendations for SMEs managers, meta-organizations' coordinators, and business regulators, geared towards enhancing the participation and performance of meta-organizations - considered as platforms of collective action - in international business transactions.

\section{Methodology}

To investigate and map the structural and functional characteristics of meta-organizations as platforms for SMEs' internationalization, we apply an inductive methodology based on a comprehensive literature review and interpretation in several inter-connected research areas. Our research starts with an overview of the main theories of internationalization - and specifically SME internationalization, focusing then on the interpretation provided by network theory, leading to international entrepreneurship and inter-organizational relations. The interorganizational relation field points then towards the institutional network theory, which is jointly studied by organization and economic studies, that complement each other to describe and explain the role of meta-organizations in the present economy, as well as the particularities of their structure and functioning, focusing on the main opportunities and challenges provided to the member organizations. 
The secondary data collection, analysis and interpretation was realized during a recursive research process: each domain of interest was investigated through an in-depth literature review, which provided insight and knowledge about main theories and concepts relevant for our investigation, and which further pointed towards topic of interest providing theoretical bridges with the complementary areas of research and through a gradual discovery, interpretation and accumulation of knowledge, with various research streams providing complementary information, insights and arguments regarding the complex and multidimensional concept of meta-organization. Our original contribution is expressed through positioning and interpreting the meta-organizational concept in the context of internationalization theory and practice, as a potential platform for effective SMEs' internationalization.

\section{SME internationalization theories and models}

Traditionally, international business was the realm of large companies, SMEs' activities having mostly a local or regional scope (Dana et al, 1999; Wright \& Dana, 2003). From an economic perspective, the internationalization of multinational companies was successfully described and explained by the eclectic paradigm, developed and then refined by Dunning (1979, 2000), stating that large corporations develop their international activities using foreign direct investments, in order to achieve ownership, location and internalization advantages. In the 1970s, however, evidence increasingly emerged that some SMEs were taking advantage of foreign market opportunities, but using different methods and internationalization paths than did large corporation. The growing body of research into SMEs internationalization subsequently developed a series of explanatory models that focus on the firm and/or the entrepreneur as the unit of analysis. These two perspectives are often combined in all the major theories of SMEs' internationalization. The reason for this dual vision is the overwhelming influence of the owner-manager(s) profile and behaviour on the strategy and activity of the small firm.

\subsection{The Uppsala model}

The Uppsala model focuses on exporting firms, neglecting other possible internationalization paths. The evolution of an SME from a mainly domestic activity to a fully international profile is described as a slow, incremental process, which involves the gradual acquisition, integration, and use of knowledge concerning the characteristics of foreign markets, as well as an increasing commitment of company's resources towards international activities. The concept of psychic distance - defined as differences in factors such as language, culture and political systems between the domestic market of the firm and the targeted foreign market (Johanson \& Wiedersheim-Paul, 1975) - is central to the model. This perspective predicts that a firm will first target the countries with a low psychic distance, in order to reduce the perceived risk of international operations and to increase the efficiency of information flows between the firm and the foreign market (Johanson \& Vahlne 1977; 1990). Johanson and Mattsson (1986) suggest that some firms may initiate their internationalization process using foreign agents, already established in the target markets, in an attempt to reduce the need for investment and risk-taking in the early stages of the internationalization process. 


\subsection{The Management Innovation model}

This model, also focusing mainly on export-oriented SMEs (Cavusgil 1980; Czinkota 1982; Reid 1981), explains the initiation and development of internationalization through a series of management innovations implemented within the firm. The original theory created by Bilkey and Tesar (1977) suggests the existence of successive organizational learning stages, which gradually increase the firm's knowledge base and, subsequently, its capacity to target and enter foreign markets. The Management Innovation model also emphasizes the role of the decisionmakers in firm's internationalization process (Collinson \& Houlden, 2005). Reid (1981) indicates that firm managers' attitude, experiences, motivation and expectations will significantly impact the path and speed of the internationalization process. Reuber and Fischer (1997) consider that the international knowledge and experiences of the owner-entrepreneur or of the firm's management team may help SMEs to jump the initial stages of internationalization.

\subsection{The Born Global / International New Ventures model}

Although the stage-based models provided a logical framework that could explain the internationalization process of many SMEs, researchers also identified firms that became quickly internationalized, without following a gradual process. These firms were named Born Globals (Knight \& Cavusgil, 1996), Global Start-ups (Oviatt \& McDougall, 1994), High Technology Start-ups (Jolly et al., 1992), or International New Ventures (McDougall et al., 1994). Despite these different labels, all studies present the same organizational phenomenon: small firms, characterized by a strong entrepreneurial and market orientation, become involved in international trends in the first two-three years after their inception, and apply cutting-edge technology to speed-up innovation and internationalization (Knight \& Cavusgil, 1996, 2004). The rapid internationalization of these firms was facilitated by a series of trends in the world economy (Madsen \& Servais, 1997), such as the fragmentation and markets, the development of new market niches, and the growing availability of internationalization information and resources; the entrepreneurial orientation, capabilities and skills of the owner-manager (Shih \& Wickramasekera, 2011), and the increased popularity of strategic alliances as means to access information or complementary resources required for international expansion (Freeman et al., 2006).

This model has outlined the entrepreneurial nature of the SMEs internationalization process, outlining the importance of entrepreneurial orientation for organizational competitiveness and success in foreign markets: "International entrepreneurship is a combination of innovative, proactive, and risk-seeking behaviour that crosses national borders and is intended to create value in organizations." (McDougall \& Oviatt, 2000, p. 903). This definition was later modified, the international entrepreneurship phenomenon being characterized as "the discovery, enactment, evaluation, and exploitation of opportunities - across national borders to create future goods and services" (Oviatt \& McDougall, 2005, p. 540).

\subsection{Reconciling the internationalization research streams}

Despite the apparent dichotomy between the stage-based and born global internationalization models, Madsen and Servais (1997) indicate that in most cases we encounter a combination of the two model, as even the Born Globals may follow an evolutionary path towards internationalization, which is often not taken into account by researchers. These apparent contradictions can be reconciled by shifting the focus of the analysis from firm to the 
entrepreneur, and considering the central influence of the owner-entrepreneur on the strategic orientation and activities of the firm (Manolova et al., 2002). Johanson and Vahlne (1977) adopt the perspective of a start-up firm, for which current business activities are often the only or the prime source of experiential knowledge. However, when the founder of a Born Global has prior knowledge and experience regarding the specificities of international markets in a particular industry, the internationalization decisions and commitments do not necessarily have to be slow and incremental (Madsen \& Servais, 1997). On the other hand, the required knowledge and experience can also be accessed from external sources, using a networking strategy (Bell, 1995).

\subsection{The relational perspective}

Using a relational perspective (Dyer \& Singh, 2007), firms can internationalize not only by using internal resources and knowledge, but also by accessing the necessary assets through partnerships and networks (Dana, 2001; Etemad et al., 2001). Thus, rapid and effective internationalization is not any more a matter of solving foreign country specific challenges, but rather to getting integrated into the appropriate networks and findings the necessary partners to produce and exchange relevant knowledge (Johanson \& Vahlne, 2009). On the other hand, the international entrepreneurship approach outlines the importance of the personal contacts identified and developed by the owner of the SME: "After an entrepreneurial actor discovers or enacts an opportunity and perceives the technologies that enable internationalization and the competitors that motivate it, the entrepreneur uses established network links that cross national borders to explore where and how quickly the opportunity can be exploited in foreign locations." (McDougall \& Oviatt, 2000, p. 544). Inter-firm and inter-personal relationships, and the resulting networks can thus be defined as an extended resource base that needs to be accessed, nurtured and exploited.

SMEs can use a relational approach to access complementary resources (Gurau, 2008) either by getting integrated in groups of other small firms, developing symbiotic relationships with large corporations, or using a combination of these two strategies. A growing stream of literature (Dana et al., 1999, 2000, 2008; Wright \& Dana, 2003) describes the symbiotic relationships developed between small firms and multinational enterprises, as an increasingly popular relational strategy for SMEs' internationalization: "In the contemporary global business environment, SMEs and MNEs increasingly have the potential to complement each other, resulting in new, synergistic relationships. MNEs are more often using SMEs for specialized tasks involving inventiveness, creativity, and local expertise; while SMEs benefit from the large resource base and the global-market reach of the MNEs." (Dana et al., 1999, p. 101). However, the organizational power unbalance between these partners can raise important challenges for the small firm (Acs et al., 1997; Wright et al., 2007), which may - formally or informally - be integrated into the hierarchical system of the multinational corporation, becoming totally dependent of the resources controlled by the large organization (O'Farrell et al., 1998).

The growing role of symbiotic relationships and networks actuates the liability of interorganizational coordination, as the available resources are not under the full control of any single organization, but rather an object of collaboration, negotiation and exchange. From this perspective, Johanson and Vahlne (2009) predict that "international business network coordination will become an increasingly important phenomenon with strong implications for firm-specific advantage as well as for internationalization" (p. 1486). Relational strategies are 
thus characterized by three central elements: (i) the integration of the firm into a network of partnerships; (ii) the use of these relationships to pool, develop, exchange or access resources; and (iii) the necessity of business network coordination.

\section{Meta-organizations as enactment of the relational strategy}

The three characteristics of the relational strategies presented above point towards the concept of meta-organization (Ahrne \& Brunsson, 2008). A relatively new concept in business theory and practice, meta-organizations are defined as: "networks of firms or individuals not bound by authority based on employment relationships, but characterized by a system-level goal" (Gulati et al., 2012, p. 573). They represent a new form of inter-organizational or inter-personal coordination, which is not based on formal authority, and which can be considered as a unit of analysis, that incorporates two inter-dependent levels of action: a network level, which includes the participant organizations, their inter-organizational relationships and the system of mutual coordination; and a meta-organizational level, focused on the positioning, strategy and activities of the meta-organization, as an integrated business organizational unit.

Yet, this level of integration may vary both from one network to another, as well as in time, for the same network. Gulati et al. (2012) identify four meta-organizational designs, determined by (a) the permeability of boundaries and (b) the degree of hierarchical stratification. Each of the four resulting meta-organizational types: (i) closed community - closed boundaries and low hierarchical stratification; (ii) open community - closed boundaries and low hierarchical stratification; (iii) extended enterprise; or (iv) managed ecosystem - open boundaries and low hierarchical stratification, create various inter-organizational contexts that manifest and evolve differently over time.

Another useful typology that points toward relevant differences in the type and scope of interorganizational coordination is suggested by Viachka (2013); meta-organizations may be created by firms established in a specific geographical location (clusters), by firms from the same sector (professional associations), or as a combination of location and sectoral association (sectoral clusters). In addition, a firm is often participating in different networks and meta-organizations, assuming various roles and targeting different organizational objectives.

In our opinion, meta-organizations represent a specific type of inter-organizational network. The necessity of this conceptual clarification is determined by the ambiguity created by various definitions and interpretations of networks (Knight \& Pye, 2006), and by the different perspectives that can be adopted for their analysis (Oliver \& Ebers, 1998; Powell \& SmithDoerr, 1994). For example, some authors (Coviello \& Munro, 1997; Johanson \& Vahlne, 1992) indicate that markets are structured as networks, which means that any active business organization is automatically part of one or several (market) networks, which are based on the exchange relationships which connect firms to each other during market transactions (Rietveldt \& Goedegebuure, 2014). However, from the perspective of economic theory, the arm-length transactions between the various buyers and sellers embedded in a market are the result of independent acts based on the self-interest of each participant, these actors having no direct relationship with each other (Investopedia.com), which contradicts the definition of markets as networks. 
To distinguish between 'markets as networks' and 'meta-organizations as networks', we consider meta-organizations as institutional forms that cover the intermediate area between markets and hierarchies (Elsner et al., 2009). These three institutions are considered in the economic theory as the main forms of reducing the transaction costs associated with interorganizational transactions; however, the dichotomy of markets versus hierarchies, as idealized and extreme forms of reducing transaction costs, is hardly in line with the present market realities. Critics of this neo-classical perspective (Elsner, 2005; Langlois, 2003; Wright \& Mukherji, 1999) emphasize that, on the one hand, abstract markets in which the contact between various business actors is exclusively mediated by price, and, on the other hand, powerful hierarchies which optimize the costs of repetitive transactions though organizational boundaries, internalization and control, do not provide effective answers to the challenges of the modern-day economy, characterized by uncertainty, hyper competition, and extreme turbulence: "In times of de-regulation and 'dis-embedding' of the 'markets', of global spatial and functional fragmentation of value-added chains in the face of complex products, and, thus, required technological interoperability and net-technologies, interdependent decision-making and coordination and cooperation problems have come to dominate the economy." (Elsner et al., 2009, p. 5). A combination of these two extreme models may represent the best solution to these problems, increasing competitiveness through a combination of organizational specialization, collaboration and inter-organizational coordination, which enhances the flexibility and adaptability of dynamic meta-organizational structures: "With complex structure, evolutionary process, and emergence, the 'boundaries of the firm' become not only shifting but also fuzzy, and both the vertical and horizontal boundaries then do not only depend on technological opportunities, but on complementary capabilities, absorptive and learning capacities, and path dependencies, and external relations of the firm [...]" (Elsner et al., 2009, p. 4)

As embodiments of the network concept, meta-organizations are fundamentally different from markets and hierarchies (Fukuyama, 1999). While markets are organized around competition, and the structure and functioning of public or commercial organizations are based on authority and obedience, the governance logic of networks is centred on negotiation and purposeful cooperation over time (Mayntz, 1993). On the other hand, as the members of the metaorganization retain their status of independent organizations, it is possible that they enter in competition one with each other, or even with the meta-organization as a whole (Berkowitz \& Dumez, 2016). The paradoxical co-existence of inter-organizational collaboration and competition leads to a situation of coopetition (Bengtsson \& Kock, 2014), which can create tensions between the interests of various meta-organizational members (Dumez, 2008).

Considering the insights provided by the economic, organization and entrepreneurship theory, we trace the following characteristics of meta-organizations:

- they represent networks or associations of organizations that can have different profiles, interests, activities and sizes, which have reached consensus to participate to pursue a systemlevel goal that may provide benefits, but also risks, for all the members; 
- $\quad$ by integrating and representing a multitude of independent organizations, the metaorganization constitutes a second-order organizational unit which has its own identity and strategy;

- the integration of the members in a meta-organization is based on an clearly expressed decision - which can be implicit or explicit, and expressed in a formal or informal way - made by each member, which is usually manifested through adherence to a set of rules which determines the structure, functioning and governance of the meta-organization;

- the members commit and pool resources to enact the structure, activity and governance of the meta-organization, usually on a long-term basis;

- the manager of each member has a dual role - on the one hand to manage and coordinate the activity of its organization, and, on the other hand, to participate to the governance of the meta-organization through its active participation in the representative coordination bodies/committees; these functions permit not only to provide managerial resources and skills to the meta-organization, but also to defend the position and the interest of the member organization;

- meta-organizations are based on a logic of negotiation and long-term cooperation, which involves, in time, the development of a common culture of trust and a convergent strategic vision;

- the governance and control of meta-organizational members is realized using formal and informal institutions, rules, procedures and customs.

- the meta-organization structure and functioning is based on the coexistence of diverse organizational structures and interests, which are addressed, expressed and reconciled through a dynamic equilibrium between cooperation and competition between participating members.

\section{Meta-organizations as collective entrepreneurial strategies}

The federative nature of meta-organizations combined with their structure and functioning as a unique unit of strategic action indicates the potential applicability of a collective entrepreneurship model, defined as "the emergence of jointly owned patron-controlled entities seeking rents at multiple levels exhibiting group innovation attributes, opportunity-seeking behaviour and uncertainty-bearing characteristics" (Cook \& Plunkett, 2006, p. 427) or of collaborative entrepreneurship perspective (Miles et al., 2005) which is centred on an organization composed of firms from different industries, that collaboratively pursue a joint strategy of continuous innovation.

These two models clearly share common elements with the structure, functioning and objectives of meta-organizations. The association of several small firms to address a market opportunity, that is too large and/or too complex for each individual organization, demonstrates strong entrepreneurial vision and creativity by combining market orientation and associational strategies. On the other hand, the symbiotic business relationship developed between large and small firms may be used by the multinational corporations to rekindle their entrepreneurial and innovative spirit, and apply a more daring and flexible approach to market opportunities. 
In our opinion, the application of the entrepreneurial orientation concept to meta-organizations should differentiate between the member firm level and the meta-organizational level. On the one hand, the firm that decides to integrate a meta-organizational structure demonstrates proactivity and innovativeness; however, collective action and coordination do not indicate the entrepreneurial propensity to take risk, but represent risk reduction strategies. On the other hand, the meta-organization as unit of analysis can apply a full entrepreneurial orientation, taking advantage of the larger pool of resources and capabilities created through interorganizational association and collaboration. This collective/collaborative form of entrepreneurship may thus represent the ideal organizational solution to enhance the risk-taking capacity at meta-organizational level, while reducing and mitigating the risk at firm level.

Considering the meta-organizational structure and functioning from an evolutionary perspective, we can posit the gradual transformation over time, of collective/collaborative entrepreneurial relations and actions into a community entrepreneurship project (Pierre et al., 2010). This change is determined by the development, through repeated interactions and transactions, of a series of inter-organizational trust-based routines, practices and symbols, which may form the fabric of an integrated meta-organizational culture. In comparison with a simple inter-organizational collaboration founded on the short-term, opportunistic convergence of individual interests, which is specific for the collective forms of entrepreneurship, community entrepreneurship builds upon shared values and principles developed through a common inter-organizational history and culture (Peredo \& Chrisman, 2006).

\section{The role of meta-organizations in SME internationalization}

When initiating the internationalization process, most SMEs are confronted with: (i) the liabilities of expansion - expressed through the additional costs of conducting cross-border transactions (Zaheer, 1995); (ii) newness - determined by the novelty of the foreign market environment that raises the transaction costs for an inexperienced firm (Teece, 1986); (iii) foreignness - entering a foreign market which has different institutions and rules of behaviour creates challenges for an SME which is lacking the understanding provided by a shared history and business context (Zaheer, 2002); and (iv) perceived risk - the previous three liabilities increase the economic, political, technological risk of entering a foreign market, which is exacerbated because local competitors have better knowledge of domestic regulatory frameworks and business rules (Ahuja, 2000).

Although relational strategies are nowadays considered as highly effective in enhancing and speeding SMEs' internationalization by addressing these liabilities, research remains focused mainly on the patterns of firm internationalization rather than on the structure and functioning of the network itself (Falize \& Coeurderoy, 2012). This issue is directly related with the unit of analysis adopted by internationalization studies of SMEs- that are usually centred on the firm or the entrepreneur (Wright et al., 2007). Although we recognize the validity of this approach, the increased application of the network theory and popularity of associational strategies for SMEs' internationalization require a paradigm shift, in which meta-organizations as networks of coordinated organizations are also considered as a valid unit of analysis. This paradigm shift is supported by the triple perspective on networks developed by the organization and management literature (Knight \& Pye, 2006): networks as logic of organizing, networks as an 
analytic perspective, and networks as a systemic entity that can be regarded as a unit within the organizational domain. The interdependence of these three complementary perspectives indicates the multilevel and paradoxical nature of the network as unit of analysis in international business studies, and requires a clear delimitation and definition of the adopted interpretative approach. For example, networks can be viewed as the logic of organizing the web of transactions and relationships that form an international market; or, by studying the relationship portfolio of a specific firms, the analytical perspective of networks can be applied to identify the relational units, their network position, and the strength or frequency of links between them; finally, by considering the coordinated network as an actor within the organizational domain, we shift the analysis from the level of the firms integrated into the network to the level of metaorganization which participates in its own name to cross-border activities.

To clearly situate the role of meta-organizations in SMEs' internationalization, it is necessary to consider the activities that can be defined as international. Extant literature takes an implicit view that internationalization is mainly selling to international customers, but this limits significantly the scope of international activities. Some firms may be integrated in cross-border value networks without even having a final product or service to offer - as it is the case of small biotech firms that often initiate their international operations through cross-border purchasing (Gurau, 2007). For this reason, we define internationalization as the performance of any activity that creates value using a cross-border exchange. This definition is compatible with the existing definitions of international entrepreneurship (McDougall \& Oviatt, 2000; Oviatt \& McDougall, 2005), if we consider that these cross-border value creation activities represent the result of identifying, addressing and exploiting market opportunities. This extended internationalization domain includes meta-organizations that focus partially or exclusively on cross-border purchasing activities - such as the groups or cooperatives of buyers - by aggregating the demand of a large number of small clients to increase bargaining power and obtain lower prices per unit of acquisition.

A potential typology of meta-organizations is their categorization in terms of the homogeneity/heterogeneity of their members. From this perspective, we distinguish homogeneous meta-organizations such as professional associations, from heterogeneous ones, comprising organizations from different economic sectors, and from combined metaorganizations, which integrate the two previous forms. The prototype of the homogeneous meta-organization is the cooperative, defined as "an autonomous association of persons united to meet common economic, social, and cultural goals. They achieve their objectives through a jointly-owned and democratically-controlled enterprise." (European Commission, 2018), while the heterogeneous one is similar with an integrated value chain (Porter, 1985) which represents the meta-organization as a system, made up of subsystems (members) each with inputs, transformation processes and outputs, that are logically connected through the complementarity of their productive activity which ultimately results in a final product. Meta-organizations can also be considered 'born global' when their members are localized in different countries, or 'gradually-globalized' when they followed a stage-model to internationalize.

The internationalization approach of meta-organizations can be either proactive or reactive: in the first case, the meta-organization is initially created to facilitate members' activity in a regional or national market, and then, the increased globalization provides opportunities for international expansion that are identified and addressed; in the second case, the creation of the 
meta-organization may be determined by a demand which is either too large or too complex for an independent organization. As a reaction to this opportunity, a meta-organization is specifically created to address the demand, attracting the number and the profile of organizations that can provide the necessary quantity and quality of the required product or service.

Considering that meta-organizations are second-order systems composed of a series of independent organizations, but which act as unitary entities in international transactions, we may encounter the situation in which all the members of the meta-organization are domestic organizations, while the activity and scope of the meta-organization is international. However, the most frequent case is when some members of the meta-organization are already internationalized, providing a bridge head for the cross-order activity of the meta-organization.

\subsection{The relevance of meta-organizations for the internationalization of European SMEs}

Meta-organizations are a global phenomenon, but, from an internationalization perspective, we posit that European SMEs can particularly benefit of this associative form of interaction and coordination. First, Europe is a unique agglomeration of countries within the world (Ratten et al., 2007). European countries are diverse in size, political background and economic development. Europe has both island economies and transition economies and its developed economies range from the very small (for example, Vatican City) to the very powerful (for example, France, Germany or United Kingdom). Moreover, Europe is influenced by the two major world trade networks, the European Union (EU) and the World Trade Organization (WTO) that provide many opportunities for foreign direct investment (FDI) and export.

Second, despite their differences in the level of development, European countries can be defined as predominantly liberal economies, characterized by a globalized offer and demand (as the many available products and services, but also the buyers, sellers and intermediaries acting on these markets foreign are foreign), hyper-competition, and a highly developed institutional framework, both at national and at European level.

Third, all Europe economies contain a large proportion of SMEs - in fact, more than $99 \%$ of the business organizations (Airaksinen et al., 2015). These firms are often confronted with a competitive conundrum: although rich in opportunities and institutional support, the European markets are too small, too competitive and too internationalized to provide a safe option for survival and development. On the other hand, despite the geographical proximity of the other European markets, the psychic distance between these countries is still significant, despite the harmonization of commercial legislation amongst European Union members. In these conditions, even an exporting activity in another European country should be treated as an international operation, requiring resources and knowledge that are often beyond the capability of a small company. For these reasons, associational strategies, and the resulting metaorganizations, can represent an effective platform for the internationalization of European SMEs. The European Union has even created an institutional form to facilitate the creation and functioning of transnational meta-organizations: "The European Cooperative Society (SCE) is an optional legal form of a cooperative. It aims to facilitate cooperatives' cross-border and transnational activities. An SCE must unite residents from more than one EU country." (European Commission, 2018). 
Although research on the international activity of meta-organizations is still rather scarce, the extant literature contains several interesting examples of European associations and cooperatives that developed an international or even a global business presence, such as: the Austrian, Dutch, French and German cooperative banks (Howarth \& Quaglia, 2016), the Mondragon Cooperative Complex founded in the Basque region of Spain (Errasti et al., 2003), the Italian productive cooperatives (Leite \& Duaibs, 2017), cooperatives from the dairy and meat industry from Denmark, Germany and the Netherlands (Theuvsen \& Ebneth, 2005), or the Portuguese industrial business associations (Costa et al., 2017). Future research should further develop this topic, providing a more detailed analysis of the benefits and challenges offered by meta-organizations as an internationalization platform for European SMEs from various countries and different economic sectors, as well as a deeper insight into the development and coordination of international operations.

\section{Meta-organization's creation and governance}

The economic rules involved in meta-organization's creation and governance stem, on the one hand, from the intermediary position of meta-organizations as networks between markets and hierarchies (Elsner et al., 2009), and, on the other hand, from the double level of its structure and functioning - independent members and the coordinated meta-organization (Gulati et al., 2012; Viachka, 2013).

As intermediate organization forms between markets and hierarches, meta-organizations are well positioned to minimize transaction costs and aggregate distributed resources in a coordinated system of value creation: "the real-world organizational dimension builds upon direct interdependence and direct interaction processes, cumulatively learned and habituated forms of cooperation to overcome social dilemmas and solve coordination problems" (Elsner et al., 2009).

From the perspective of a dual-level system, that includes the members' level and the metaorganizational level of perception, management and action, which are coexistent and interdependent, the meta-organization structure and functioning raises challenges in solving transaction costs, agency, and resource-dependency problems: "According to the Transaction Costs Economics, organizations are driven by the need of reducing costs when interact with each other; according to the Agency theory, organizations are driven by the need of aligning the behaviours or outcomes of the other parties to expectations; according to the Resource Dependence theory, organizations are driven by the need to control the resources that are critical to them." (Rossignoli \& Ricciardi, 2015, p. 7).

To overcome the natural tendency of SMEs to preserve at all costs their autonomy, the firm manager should be convinced that by participating in a meta-organization it can reduce significantly the transaction costs and access indispensable resources for national and international competitiveness (Viachka, 2013). Although the meta-organization, by definition, includes members that remain independent in terms of strategic decision and management, in order to achieve a real coordination each member organization needs to surrender, permanently or temporarily, some autonomy (Ahrne \& Brunsson, 2010). Whereas this seems to contradict the basic tenet of a meta-organization, this transfer of authority from organizational to meta- 
organizational member is validated by the freedom preserved by each member to reverse this decision at any time, and by the direct participation of each firm's manager(s) to the collective decision making, implementation and coordination of the meta-organization (Gulati et al., 2012). In fact, this collective and democratic participation to meta-organizational governance and management - well expressed in the cooperative model of governance - is the only possibility to avoid agency and opportunistic behaviour problems, ensuring a fair mobilization of resources and an equitable distribution of benefits or losses amongst meta-organizational members.

However, to achieve superior management efficiency, some meta-organizations may adopt a trilateral form of governance building "a separate, external, management entity composed of professional agents in order to monitor the parties' behaviours and to administer the process of collective decision making" (Park, 1996, p. 812), in which case, agency problems may resurface, as information asymmetries will emerge between member organizations and the central management bodies.

The level of initial coordination between the members of a meta-organization will be determined by the inter-organizational psychic distance - which can be significant, especially in transnational meta-organizations. Collaboration and coordination will usually improve with time, as repeated interactions between members leads to inter-organizational trust, but also to the development and enactment of common routines, procedures and symbols that progressively result in a distinctive meta-organizational culture. On the other hand, interorganizational coordination requires also the existence and application of specific control mechanisms, which can be either formal managerial control procedures, or an informal control rooted in inter-organizational and inter-personal culture (Dekker, 2004).

The economic rules of meta-organizations have been mainly analysed in relation to domestic inter-organizational networks, the international or transnational element being largely neglected. This knowledge gap requires further investigations regarding the importance and impact of international dimensions on the creation, structure, functioning, and governance of meta-organizations.

\section{Concluding recommendations and remarks}

This study investigates the relevance of the meta-organizational concept for the SMEs' internationalization theory and practice. Although meta-organizations have many common elements with the network theory, in our opinion, they represent a specific form of networks that apply an organization institutional framework to associations of independent organizations. Despite the popularity and prevalence of meta-organizations in the modern society, the description and analysis of their structure, functioning and coordination mechanisms are still scarce, this new research stream emerging and evolving from the interpretation of interorganizational networks through the lens of organization and economic theories. Preserving this theoretical basis, we expand the research domain of meta-organizations, projecting the concept in the area of SMEs internationalization.

Our analysis reveals the complexity of the meta-organizational theory and practice, opening potential paths for further research and practical applications. As a result of our investigation, 
we formulate the following recommendations to academics, practitioners (managers) and policy makers:

- the academic research should focus more on the specific challenges raised by metaorganizations as specific forms of inter-organizational cooperation and coordination, as well as on the potential applications of this model for small entrepreneurial ventures in terms of collective entrepreneurship, strategic action, and internationalization;

- the meta-organization represents a potential development path for entrepreneurial SMEs, that should be taken into account and eventually applied by the managers of these organizations; on the other hand, the challenges raised by this associational form of organization must be properly understood and addressed to avoid potential problems and enhance the resulted benefits for the member organization;

- $\quad$ policy-makers should support more the creation and functioning of meta-organizations through institutional frameworks and proactive initiatives at local, regional and transnational levels; they also need to increase the awareness and understanding of the start-up entrepreneurs regarding the existence and the potential of this inter-organizational platform for collective action and coordination.

Despite its predominantly theoretical focus, this paper provides an original overview of the main elements that converge into the concept, theory and practice of meta-organizations, outlining their potential as effective platforms for SMEs internationalization, that can be relevant and successfully applied in the European institutional and business context.

\section{References}

[1] Acs, Z. J., Morck, R., Shaver, J. M. and Yeung, B. (1997). "The internationalization of small and medium-sized enterprises: A policy perspective," Small Business Economics, vol. 9, pp. 7-20.

[2] Ahrne, G. and Brunsson, N. (2010). "How much do meta-organizations affect their members?" Paper presented at SGIR 7th Pan-European International Relations Conference, 9-11 September, Stockholm, Sweden. Available: http://www.eisa-net.org/bebruga/eisa/files/events/stockholm/Meta-organizations.pdf.

[3] Ahrne, G. and Brunsson, N. (2008). Meta-Organizations, Cheltenham, UK: Edward Elgar Publishing.

[4] Ahuja, G. (2000). "Collaboration networks, structural holes and innovation: A longitudinal study," Administrative Science Quarterly, vol. 45, pp. 425-455.

[5] Airaksinen, A., Luomaranta, H., Alajääskö, P. and Roodhuijzen, A. (2015). "Statistics on small and medium-sized enterprises: Dependent and independent SMEs and large enterprises," Eurostat Statistics Explained. Available: http://ec.europa.eu/eurostat/statistics-explained/index.php/Statistics_on_small_and_ medium-sized_enterprises.

[6] Bell, J. (1995). "The internationalization of small computer software firms," European Journal of Marketing, vol. 29, pp. 60-75. 
[7] Bengtsson, M. and Kock, S. (2014). "Coopetition - Quo Vadis? Past accomplishments and future challenges," Industrial Marketing Management, vol. 43, pp. 180-188.

[8] Berkowitz, H. and Dumez, H. (2016). "The concept of meta-organization: Issues for management studies," European Management Review, vol. 13, pp. 149-156.

[9] Bilkey, W. J. and Tesar, G. (1977). "The export behavior of smaller Wisconsin manufacturing firms," Journal of International Business Studies, vol. 9, pp. 93-98.

[10] Cavusgil, S. T. (1980). "On the internationalization process of firms," European Research, vol. 8, pp. 273-281.

[11] Collinson, S. and Houlden, J. (2005). "Decision-making and market orientation in the internationalization process of small and medium sized enterprises," Management International Review, vol. 45, pp. 413-436.

[12] Cook, M. L. and Plunkett, B. (2006). "Collective entrepreneurship: An emerging phenomenon in producer-owned organizations," Journal of Agricultural and Applied Economics, vol. 38, pp. 421-428.

[13] Costa, E., Soares, A. L. and Pinho de Sousa, J. (2017). "Institutional networks for supporting the internationalisation of SMEs: The case of industrial business associations," Journal of Business \& Industrial Marketing, vol. 32, pp. 1182-1202.

[14] Coviello, N. and Munro, H. (1997). "Network relationships and the internationalization process of small software firms," International Business Review, vol. 6, pp. 361-386.

[15] Czinkota, M. R. (1982). Export development strategies: U.S. promotion policies, New York, NY: Praeger.

[16] Dana, L.-P. (2001). "Networks, internationalization \& policy," Small Business Economics, vol. 16, pp. 57-62.

[17] Dana, L.-P., Etemad, H. and Wright, R. W. (1999). "The impact of globalization on SMEs," Global Focus, vol. 11, pp. 93-105.

[18] Dana, L-P., Etemad, H. and Wright, R. W. (2000). "The global reach of symbiotic networks," Journal of Euromarketing, vol. 9, pp. 1-16.

[19] Dana, L-P., Etemad, H. and Wright, R. W. (2008). "Toward a paradigm of symbiotic entrepreneurship," International Journal of Entrepreneurship and Small Business, vol. 5, pp. 109-126.

[20] Dekker, H. C. (2004). "Control of inter-organizational relationships: Evidence on appropriation concerns and coordination requirements," Accounting, Organizations and Society, vol. 29, pp. 27-49.

[21] Dumez, H. (2008). "Les méta-organisations, “Le Libellio d'Aegis, vol. 4, pp. 31-36.

[22] Dunning, J. H. (1979). "Toward an eclectic theory of international production: Some empirical tests," Journal of International Business Studies, vol. 11, pp. 9-31.

[23] Dunning, J. H. (2000). "The eclectic paradigm as an envelope for economic and business theories of MNE activity," International Business Review, vol. 9, pp. 163-190. 
[24] Dyer, J. H. and Singh, H. (2007). "The relational view: Cooperative strategy and sources of interorganizational competitive advantage," Academy of Management Review, vol. 23, pp. 660-679.

[25] Elsner, W. (2005). "Real-world economics today: The new complexity, co-ordination, and policy," Review of Social Economy, vol. LXIII, pp. 19-53.

[26] Elsner, W., Hocker, G. and Schwardt, H. (2009). "Simplistic vs. Complex Organization: Markets, Hierarchies, and Networks in an 'Organizational Triangle'," MPRA Paper No. 14315. muenchen.de/14315/1/Simplistic_vs._Complex_Organization-

Available: https://mpra.ub.uniMarkets_Hierarchies_and_Networks_in_an_Organizational_Triangle.pdf

[27] Errasti, A. M., Heras I., Bakaikoa, B. and Elgoibar, P. (2003). "The internationalization of co-operatives: The case of the Mondragon Co-operative Corporation," Annals of Public and Cooperative Economics, vol. 75, pp. 553-584.

[28] Etemad, H., Wright, R. W. and Dana, L-P. (2001). "Symbiotic international business networks: Collaboration between small and large firms," Thunderbird International Business Review, vol. 43, pp. 481-499.

[29] European Commission (2018). Cooperatives. Available: https://ec.europa.eu/growth/sectors/social-economy/cooperatives_en.

[30] Falize, M. and Coeurderoy, R. (2012). "The network approach to rapid internationalization among Born-Global and Born-again Global firms: The case of the Global Innovation Network," Working paper. Louvain School of Management, Belgium. Available: $\quad$ https://cdn.uclouvain.be/public/Exports\%20reddot/sshilsm/images/LSM_wp_RENT(Falize-Coeurderoy).pdf.

[31] Freeman, S., Edwards, R. and Schroder, B. (2006). "How smaller born-global firms use networks and alliances to overcome constraints to rapid internationalization," Journal of International Marketing, vol. 14, pp. 33-63.

[32] Fukuyama, F. (1999). The Great Disruption: Human Nature and the Reconstitution of Social Order, London, UK: Profile Books.

[33] Gulati, R., Puranam, P. and Tushman, M. (2012). "Meta-organization design: Rethinking design in interorganizational and community contexts," Strategic Management Journal, vol. 33, pp. 571-586.

[34] Gurau, C. (2007). "The "Born Global Purchasers": Internationalisation through outsourcing in the UK biotechnology sector," Paper presented at the 2007 Oxford Business \& Economics Conference. Available: http://www.gcbe.us/2007_OBEC/data/Calin\%20Gurau.doc.

[35] Gurau, C. (2008). "An exploratory analysis of the strategic marketing choices implemented by the UK biopharmaceutical SMEs," International Journal of Entrepreneurship and Small Business, vol. 6, pp. 245-263.

[36] Gurau, C. and Ranchhod, A. (2007). "The internationalisation of biotech SMEs: A comparative analysis of UK and US firms," in Rialp, A. and Rialp, J. (Eds.), International 
Marketing Research: Opportunities and Challenges in the 21st Century, Advances in International Marketing, vol. 17 (pp. 137-158). Oxford, UK: JAI Press.

[37] Howarth, D. and Quaglia, L. (2016). "Internationalized banking, alternative banks and the Single Supervisory Mechanism," West European Politics, vol. 39, pp. 438-461.

[38] Johanson, J. and Mattsson, L. G. (1986). "International marketing and internationalization process: A network approach," in Paliwoda, S., \& Turnbull, P. (Eds.), Research in International Marketing, London, UK: Croom Helm.

[39] Johanson, J. and Vahlne, J. (1977). "The internationalization process of the firm - a model of knowledge development and increasing foreign market commitments," Journal of International Business Studies, vol. 8, pp. 23-32.

[40] Johanson, J. and Vahlne, J-E. (1992). "Management of foreign market entry," Scandinavian International Business Review, vol. 1, pp. 9-27.

[41] Johanson, J. and Vahlne, J. (1990). "The mechanism of internationalization," International Marketing Review, vol. 7, pp. 11-24.

[42] Johanson, J. and Vahlne, J. E. (2009). “The Uppsala internationalization process model revisited: From liability of foreignness to liability of outsidership," Journal of International Business Studies, vol. 40, pp. 1411-1431.

[43] Johanson, J. and Wiedersheim-Paul, F. (1975). "The internationalization of the firm: Four Swedish cases," Journal of Management Studies, vol. 12, pp. 305-322.

[44] Jolly, V. K., Alahuta, M. and Jeannet, J.-P. (1992). "Challenging the incumbents: How high technology start-ups compete globally," Journal of Strategic Change, vol. 1, pp. 7182 .

[45] Knight, G. A. and Cavusgil, T. (1996). "The born global firm: A challenge to traditional internationalization theory," Advances in International Marketing, vol. 8, pp. 11-26.

[46] Knight, G. A. and Cavusgil, S. T. (2004). "Innovation, organizational capabilities, and the born-global firm," Journal of International Business Studies, vol. 35, pp. 124-141.

[47] Knight, L. and Pye, A. (2006). "Multiple meanings of 'network': Some implications for interorganizational theory and research practice," Working Paper Series, School of Management, University of Bath, UK.

[48] Langlois, R. N. (2003). "The vanishing hand: The changing dynamics of industrial capitalism," Industrial and Corporate Change, vol. 12, vol. 351-385.

[49] Leite, M. de P. and Duaibs, R. (2017). "Cooperatives and productive internationalization: A new challenge," Sociologia \& Antropologia, vol. 7, pp. 521-543.

[50] Madsen, T. K. and Servais, P. (1997). "The internationalization of born globals: An evolutionary process?” International Business Review, vol. 6, pp. 561-583.

[51] Manolova, T. S., Brush, C. G., Edelman, L. F. and Greene, P. G. (2002). "Internationalization of small firms: Personal factors revisited," International Small Business Journal, vol. 20, pp. 9-31. 
[52] Mayntz, R. (1993). "Modernization and the logic of interorganizational networks," in Child, J., Crozier, M. Mayntz, R. et al. (Eds.), Societal Change between Market and Organization (pp. 3-18). Aldershot, UK: Avebury.

[53] McDougall, P. P. and Oviatt B. M. (2000). "International entrepreneurship: The intersection of two research paths," Academy of Management Journal, vol. 43, pp. 902-908.

[54] McDougall, P. P., Shane, S. and Oviatt, B. M. (1994). "Explaining the formation of international new ventures," Journal of Business Venturing, vol. 9, pp. 469-487.

[55] Miles, R. E., Miles, G. and Snow, C. C. (2005). Collaborative Entrepreneurship: How Network Firms Use Continuous Innovation to Create Economic Wealth, Stanford, CA: Stanford University Press.

[56] O'Farrell, P. N., Wood, P. A. and Zheng, J. (1998). "Regional influences on foreign market development by business service companies: Elements of a strategic context explanation," Regional Studies, vol. 32, pp. 31-48.

[57] Oliver, A. and Ebers, M. (1998). "Networking network studies: An analysis of conceptual configurations in the study of inter-organizational relationships," Organization Studies, vol. 19, pp. 549-583.

[58] Oviatt, B. M. and McDougall, P. P. (1994). "Toward a theory of international joint ventures," Journal of International Business Studies, vol. 24, pp. 45-64.

[59] Oviatt, B. M. and McDougall, P. P. (2005). "Defining international entrepreneurship and modeling the speed of internationalization," Entrepreneurship Theory and Practice, vol. 29, pp. 537-554.

[60] Park, S. H. (1996). "Managing an interorganizational network: A framework of the institutional mechanism for network control," Organization Studies, vol. 17, pp. 795-824.

[61] Paul, J. (2015). "Market access and the mirage of marketing to the maximum: New measures," Asia Pacific Journal of Marketing and Logistics, vol. 27, pp. 676-688.

[62] Paul, J., Parthasarathy, S. and Gupta, P. (2017). "Exporting challenges of SMEs: A review and future research agenda," Journal of World Business, vol. 52, pp. 327-342.

[63] Peredo, A. and Chrisman, J. (2006). "Toward a theory of community-based enterprise," Academy of Management Review, vol. 31, pp. 309-328.

[64] Pierre, A., von Friedrichs, Y. and Wincent, J. (2014). "Entrepreneurship in society: A review and definition of community-based entrepreneurship research," in Lundström, A., Zhou, C., von Friedrichs, Y., Sundin, E. (Eds.), Social Entrepreneurship: Leveraging Economic, Political, and Cultural Dimensions (pp. 239-257). Heidelberg, Germany: Springer.

[65] Porter, M. E. (1985). Competitive Advantage, New York, NY: The Free Press.

[66] Powell, W. and Smith-Doerr, L. (1994). "Networks and economic life," in Smelser, N. and Swedberg, R. (Eds.), The Handbook of Economic Sociology (pp. 368-402). Chichester, UK: Princeton University Press. 
[67] Ratten, V., Dana, L., Han, M. and Welpe, I. (2007). "Internationalization of SMEs: European comparative studies," International Journal of Small Business and Entrepreneurship, vol. 4, pp. 361-379.

[68] Reid, S. (1981). "The decision-maker and export entry and expansion," Journal of International Business Studies, vol. 12, pp. 101-111.

[69] Reuber, A. R. and Fischer, E. (1997). "The influence of the management team's international experience on the international behaviors of SMEs," Journal of International Business Studies, vol. 28, pp. 807-825.

[70] Rietveldt, L. and Goedegebuure, R. (2014). "The influence of network relationships on the internationalization process of SMEs. A multiple case-study of Ethiopian SMEs," Working Paper No. 2014/08, Maastricht School of Management, The Netherlands.

[71] Rossignoli, C. and Ricciardi, F. (2015). "Theories explaining inter-organizational relationships in terms of coordination and control needs," in Rossignoli, C., \& Ricciardi, F. (Eds.), Inter-Organizational Relationships: Contributions to Management Science (pp. 736), Geneva, Switzerland: Springer International Publishing.

[72] Shih, T. Y. and Wickramasekera, R. (2011). "Export decisions within Taiwanese electrical and electronic SMEs: The role of management characteristics and attitudes," Asia Pacific Journal of Management, vol. 28, pp. 353-377.

[73] Teece, D. J. (1986). "Profiting from technological innovation: Implications for integration, collaboration, licensing and public policy," Research Policy, vol. 15, pp. 285305.

[74] Theuvsen, L. and Ebneth, O. (2005). "Internationalization of cooperatives in the agribusiness: Concepts of measurement and their application," in Theurl, T. and Meyer, E. C. (Eds.), Strategies for Cooperation (pp. 395-419), Aachen, Germany: Shaker.

[75] Viachka, A. (2013). "Comparing firms' associational strategies across sectors and locations: Cluster initiatives as meta-organizations". Available: https://www.hhs.se/contentassets/3f70837599df408dabbf1a22679b486c/c7_viachka.pdf.

[76] Wright, R. W. and Dana, L-P. (2003). "Changing paradigms of international entrepreneurship strategy," Journal of International Entrepreneurship, vol. 1, pp. 135-152.

[77] Wright, M., Westhead, P. and Ucbasaran, D. (2007). "The internationalization of SMEs and international entrepreneurship: A critique and policy implications," Regional Studies, vol. 41, pp. 1013-1029.

[78] Wright, P. and Mukherji, A. (1999). "Inside the firm: Socioeconomic versus agency perspectives on firm competitiveness," Journal of Socio-Economics, vol. 28, pp. 295-307.

[79] Zaheer, S. (1995). "Overcoming the liability of foreignness," Academy of Management Journal, vol. 38, pp. 341-363.

[80] Zaheer, S. (2002). "The liability of foreignness, redux: A commentary," Journal of International Management, vol. 8, pp. 351-358. 